\title{
Configuration and operation combined optimization for EV battery swapping station considering PV consumption bundling
}

\author{
Yu Cheng ${ }^{*}$ and Chengwei Zhang
}

\begin{abstract}
Integration of electric vehicles (EVs), demand response and renewable energy will bring multiple opportunities for low carbon power system. A promising integration will be EV battery swapping station (BSS) bundled with PV (photovoltaic) power. Optimizing the configuration and operation of BSS is the key problem to maximize benefit of this integration. The main objective of this paper is to solve infrastructure configuration of BSS. The principle challenge of such an objective is to enhance the swapping ability and save corresponding investment and operation cost under uncertainties of PV generation and swapping demand. Consequently this paper mainly concentrates on combining operation optimization with optimal investment strategies for BSS considering multiscenarios PV power generation and swapping demand. A stochastic programming model is developed by using state flow method to express different states of batteries and its objective is to maximize the station's net profit. The model is formulated as a mixed-integer linear program to guarantee the efficiency and stability of the optimization. Case studies validate the effectiveness of the proposed approach and demonstrate that ignoring the uncertainties of PV generation and swapping demand may lead to an inappropriate batteries, chargers and swapping robots configuration for BSS.
\end{abstract}

Keywords: Electric vehicle, Battery swapping station, Optimal facilities configuration, Uncertainty, PV consumption bundling

\section{Introduction}

Electric vehicles (EVs) are being widely concerned as an environmentally friendly transportation compared to internal-combustion-engine vehicles. The government of China introduced related policies to promote the popularization of EVs [1]. Now the popular mode complementary energy for EVs is by charging. But EVs need to wait in queue if the chargers are not enough when they arrive at the charging station. It usually takes less than half an hour for fast charging or $4 \sim 8 \mathrm{~h}$ for normal charging $[2,3]$. Battery swapping is much more flexible compared to the battery charging, especially for Taxi and other public transportations.

\footnotetext{
* Correspondence: judychengyu@163.com

School of Electrical and Electronic Engineering, North China Electric Power University, Beijing 102206, China
}

\section{Springer Open}

(c) The Author(s). 2017 Open Access This article is distributed under the terms of the Creative Commons Attribution 4.0 International License (http://creativecommons.org/licenses/by/4.0/), which permits unrestricted use, distribution, and reproduction in any medium, provided you give appropriate credit to the original author(s) and the source, provide a link to the Creative Commons license, and indicate if changes were made.
As for the power system, EV BSS can charge the batteries in advance, even during the valley period, to fulfill swapping peak demand which is highly consistent with peak demand of power system theoretically. In theory, more battery reserves makes BSS much more flexible load to consume clean energy at specific period. BSS can be regard as one kind of demand response resources to bring benefits to both power system and environment. Now in China, relevant practices of battery swapping mode have been carried out in many areas. For example, Hangzhou city launched a pilot project for taxi fleets and placed battery swapping stations into operation on the high way from city center to airport, Sichuan province and Chongqing city which together called Cheng$\mathrm{Yu}$ area are building the first inter provincial travel channel for new energy vehicle in China on the basis of battery swapping mode, trying to set up a green travel 
demonstration zone [4]. Due to energy storage feature, BSS is able to act as supplementary automatic generation control and black-start resource [5, 6]. In spite of that, the most popular and fundamental contribution of BSS is to reducing carbon emissions, facilitate renewable integration.

Optimal strategies and schedules for BSS operation have been wide reported in literatures [7-11]. A charging strategy considering service availability and selfconsumption of PV energy is proposed in [7], which proves the performance of PV-based BSS is better for both economic and environment. In [8], a detailed operation model of BSS is presented considering many different energy transfer mode like G2B, B2G, or B2B. A new optimal dispatching strategy for microgrid containing BSS is given in [9], which indicates that BSS is also able to be a kind of controllable resource to support power system. A short-term battery management and market strategy are proposed and a dynamic operation model of BSS in electricity market is built in [11].

Recent studies such as [12-15] have identified the need for combined facility configuration problem and operation strategy of BSS. The investment return of BSS is closely related to the operation strategy and schedule for daily swapping service. Therefore, it is necessary to take into account the operation strategy simulation when study on optimal configuration scheme of BSS. Swapping demand, the cost for battery, other facilities and the cost for charging should be considered synthetically while allocating the number of batteries for BSS [12]. Previous works $[16,17]$ used queuing theory to solve the EVs' swapping facilities configuration problem, while the expectation result is not applicable for some extreme cases. A multi-objective optimization problem for component capacity of PV based battery swapping station is solved in [13], aiming at maximizing the benefits of economy and environment. A capacity optimization method for PV-based BSS considering second-use of EV batteries is studied in [14]. The EV battery pack quantity planning problem under mode of centralized charging and unified distribution is researched and a comprehensive planning model is proposed in [15]. The power network reinforcement should be taken into consideration during the battery charging or swap station configuration process, and the battery charging/swap station model are developed in [18].

In the particular case of BSS regarded as one kind of demand response resources, various references have demonstrated that BSS has its unique advantages to handle adverse effects on distribution network with high penetration of EVs and distributed renewable resources benefitting both power system and environment $[5,6,9,11]$. A new supplementary automatic generation control strategy using energy storage in BSSs is proposed in [5], and the optimization model for power system restoration with support from EVs under battery swapping mode is analyzed. Research results testify it is feasible to include BSS into AGC market and power system restoration process. BSS has its own batteries to buffer the transferring of power from grid to EVs and to balance supply and demand [11], this should be commonly concerned by the system operators and load aggregators in electricity market.

Hence the demand response ability of BSS to further support renewable generation resources integration and thus system operation is closely linked with the facility configuration and operation strategy of BSS. Less attention has been paid to the facility configuration problem for enhancing BSS demand response potential, and theoretical research lags behind application which is not able to meet the demand of the development in this field [3]. Indeed the investment risk for BSS is non-negligible due to large investment scale. As a special electricity provide entity, operating profit of BSS is closely related to both swapping demand and cost for investment and operation. The investment and operation cost of BSS depends on the quantity of the batteries, chargers and the swapping robots, which affect BSS capability to meet swapping demand.

In contrast to the whole operation and capacity cost minimization modelling used to planning the batteries quantity and other facilities of BSS, a profit maximization model is developed in this study with considering how an EV BSS makes planning and operation decision considering the swapping demand, PV consumption demand and other complicated environments. The model aims at deriving the optimal solutions for components configuration in BSS and its operation schedule to recharge EV batteries. In this context, the proposed model is applied to derive evaluate the demand response potential of EV BSS which is much valuable for system operators and load aggregators in electricity market. In addition, the proposed model is able to accurately describe the operation process including issues necessary to be concerned such as customer waiting queue, which is paid less attention in previous work.

To date, there is no modeling for evaluating how facilities planning and operation for BSS can be cooptimized and simulated in order to maximize demand response profitability of BSS. Furthermore, there is currently no formal treatment in modeling the response flexibility of BSS with considering the investment scale, satisfaction of swapping service and batteries charging process. In this context, the paper attempts to contribute those problems modeling. Specifically, this paper's main contributions are: 
1) The model combines both long-term facilities configuration and short-term operation strategies optimization with maximizing profit of BSS under different stochastic scenarios of BSS operation environments. Though, coordinated operation and facilities configuration optimization model for EV charging stations are already published on some studies such as [19] and [20], there are few published works specifically on swapping stations. Previous component capacity planning works for swapping station only consider and deal with battery configuration problem. The jointed configuration problem for both batteries and chargers are investigated recently, such as models in [13] and [21]. This paper further conducts on configuration problems for batteries, chargers and swapping robots together.

2) The state flow model for EV battery is proposed to describe a group of batteries status, which is quite different from the modeling method from perspective of each individual battery condition in previous works. The state flow model for EV batteries in BSS used in this paper can identify the charging power and battery refueling process clearly. Therefore, the group of batteries in swapping, charging or idle status can be precisely formulated.

3) The proposed model of BSS considers the time and the capability for swapping operation instead of assumptions that this operation is finished immediately and the swapping capability is large enough in previous works. Consequently, this paper simulates the EVs waiting queue with taking swapping ability of BSS into account, which are more in line with reality as mentioned in [22]. In addition, this paper models the EVs waiting queue constrain as a chance constrain in the optimization model to formulate customer satisfaction with probabilistic approach.

4) The PV consumption bundling requirement is included in proposed model and the profit abilities of BSS are evaluated under different PV capacities and consumption bundling requirement levels in case study. The analysis results are able to assist to instruct a new kind of business pattern for BSS to accomplish clean energy consumption target in electricity market.

The rest of the paper is organized as follows. Section 2 describes the BSS business model, proposes the state flow model to describe battery charging process. Section 3 proposes an optimization model of configuration and operation for BSS considering PV consumption bundling. And case study and some impact discussions are presented in Section 4 and Section 5, which can provide suggestions for the grid operator to develop and recall BSS as a kind of demand response resources relieve system pressure. Finally, the conclusions are given in Section 6.

\section{Problem Descriptions}

\subsection{Business mode for BSS}

Battery swap service is available to EVs in BSS. The BSS could charge batteries by consuming PV power from PV electricity suppliers or power from the main grid during off peak time and offer swapping service by charging for fee to make profit and maintain its business. Considering TOU and the energy of PV electricity supplier can provide, BSS optimizes charging schedule in the case of satisfying customer satisfaction and PV consumption task. BSS is incentive to charge batteries during the lower price period as much as possible and consume enough PV energy to meet PV consumption requirement. This strategy can both save the electricity bills for BSS and utilize more clean energy, bringing economic benefits and increasing the efficiency of environmental reduction of EVs simultaneously.

It is worth noting that the ability BSS can serve at one time interval is influenced by both the number of EV batteries fully charged and the number of swapping robots. During high swapping demand period, EVs should wait in the queue for a short time if BSS can't provide swapping service at once.

The structure of BSS is displayed in Fig. 1 and main facilities are such as follows:

1) EV battery: the key equipment for BSS to serve EVs with swapping serve.

2) EV battery charger: the terminal to charge EV batteries in BSS.

3) Swapping robot: the machine help to swap EV batteries.

4) Control unit for optimization: the key unit for EV BSS, which is responsible for coordinate and control the equipment in BSS to optimize the operation.

\subsection{Key problems for business of BSS}

The profit level of BSS is mainly influenced by some key factors, they are as follows:

1) Swapping demand: Swapping demand is the key factor to affect BSS's income, including amount level and distribution characteristic. The large amount of swapping demand is, the more income of BSS is under normal condition. The distribution characteristic of swapping demand affects both income and demand response flexibility of BSS, but it is not in our study 


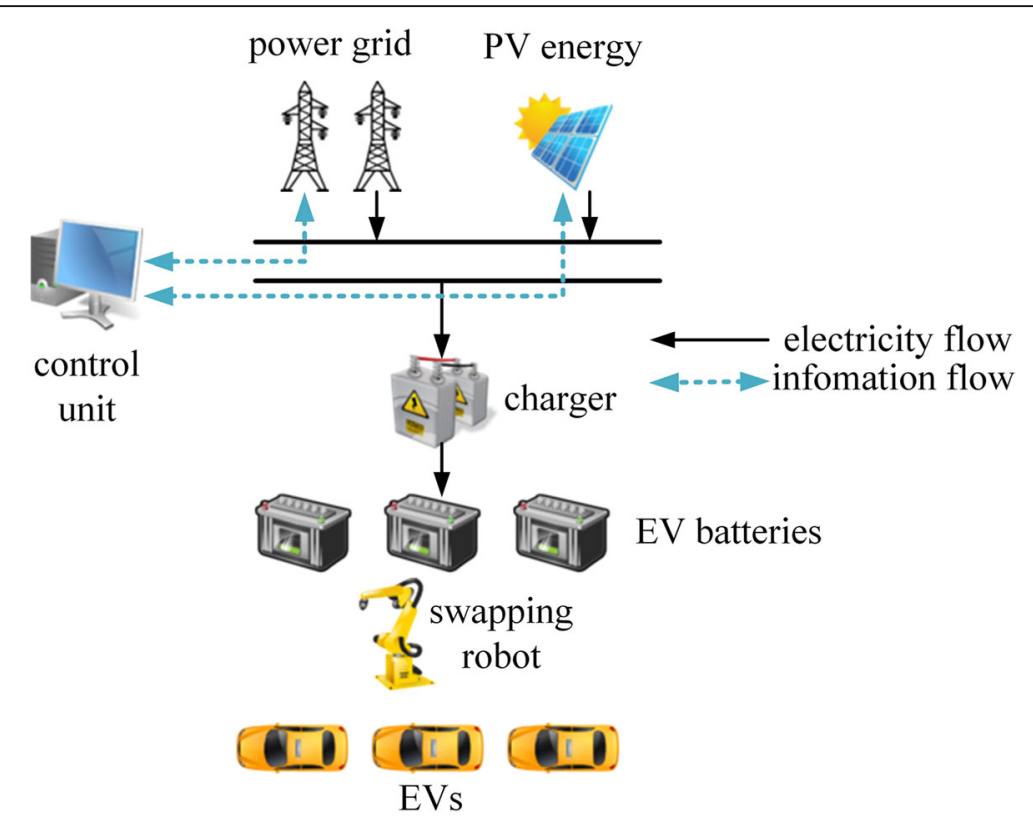

Fig. 1 BSS system

scope. More detailed discussions will be carried out in our future work.

2) Service fee for battery swapping: BSS charges for fee after finishing swapping battery for EVs. Service fee is the key point to influence the income of BSS. Income usually increases as fee increases in the case of unchanged demand. But in reality, the price elasticity of demand is not zero.

3) Electricity price level: it is the main factor influencing BSS's income, as large power consumption for charging. Generally, the lower the electricity price is, the stronger the profitability is for BSS. Considering that the price for renewable energy is usually cheaper than conventional ones, it is obviously that the more renewable energy BSS uses, the electricity bill is low, the stronger profit BSS can get.

4) Costs for facilities: As follows, EV battery, battery charger and the swapping robot are three main facilities of BSS, not a single one can be omitted. In general, the lower the cost for these facilities is, BSS can allocate more facilities to absorb cheaper electricity at the off-peak time. BSS has more decision options under this circumstance, naturally, the more profit it gets.

\subsection{Fixed cost calculation model for equipment in BSS}

At present, costs for facilities account for a major proportion in investment of BSS, the rationality to invest facilities should be concerned emphatically for EVs swapping demand is undefined nowadays. As for one specific equipment $\mathrm{n}$ in BSS, the annual average fixed cost is as follows:

$$
C_{f i x e d, n}^{\text {year }}=b_{n} \cdot \frac{r_{0}\left(1+r_{0}\right)^{m}}{\left(1+r_{0}\right)^{m}-1}
$$

Where $C_{\text {fixed }, n}^{\text {year }}$ is the annual fixed cost for facility $n ; b_{n}$ is the cost to buy and install facility $n, m$ is life time of facility $n$, generally expressed in the number of years; And $r_{0}$ is the discount rate.

\subsection{BSS customer satisfaction indexes}

Customer satisfaction of BSS is closely related with the swapping service ability and fee. The quantity of the batteries, chargers and the swapping robots affect BSS capability to meet the swapping demand. The components configuration strategies model proposed in section 3 aims to enhance the swapping ability and save corresponding investment and operation cost to meet acceptable customer satisfaction.

To characterize customer satisfaction, waiting time for available batteries and EV blocking probability are proposed to evaluate service availability in previous works $[21,22]$. Based on the EVs' waiting time for swapping service and waiting queue length in procedure simulation, most works evaluate the BSS operation from the temporal perspective and propose evaluation indexes such as Availability of Battery Swapping Service per Day (ABSSD) [21], queuing time cost per hour and average queuing length [16]. By the model in section 3, this 
paper can simulate out the length of the waiting queue at each time with maximizing the profit of BSS under acceptable customer satisfaction requirements.

The length of the waiting queue at time $\mathrm{t} L_{t}$ is used as the basic index for characterizing customer satisfaction in this paper, which is generally expressed in the number of cars and contains customers' waiting time cost information either. Based on the basic index $L_{t}$, four extended indexes to characterize customer satisfaction multi-dimensionally are defined, including maximum queue length $L_{\max }$, average queue length $\bar{L}$, normalized average queue length for each swapping demand $\overline{L_{\text {unit }}}$, and probability of queue length longer than some value $P_{\eta}$, detailed calculation formulations can be got from formula (2), (3), (4), (5). Above mentioned indexes is going to be constrained to acceptable levels in the optimization model in section 3 .

$$
L_{\max }=\max \left(L_{1}, L_{2}, \ldots, L_{t}, \ldots, L_{T-1}, L_{T}\right)
$$

Where $L_{t}$ is the length of the queue at time $t, T$ is the number of time interval in the research period.

$$
\begin{gathered}
\bar{L}=\frac{\sum_{t=1}^{T} L_{t}}{T} \\
\overline{L_{\text {unit }}}=\frac{\sum_{t=1}^{T} L_{t}}{\sum_{t=1}^{T} n_{t}^{d}}
\end{gathered}
$$

Where $n_{t}^{d}$ is the swapping demand at time $\mathrm{t}$, which is expressed as the amount of EVs that arrive at BSS for swapping. $\overline{L_{\text {unit }}}$ is normalized average queue length for each swapping demand which is obtained by dividing total queue length by total swapping demand. It can characterize the average waiting time for each EV indirectly.

$$
P_{\eta}=p\left(L_{t} \geq \eta\right)
$$

Where $\eta$ is the estimated acceptable maximum queue length, $p()$ is the probability calculation function.

\subsection{State flow model for EV battery}

There are three states of batteries in the BSS, which are state of fully charged, being charging and waiting for charging [23]. Assumes that a complete and continuous charging process takes $T_{c h}$ time intervals for an EV battery with capacity of $C$ and the charging power is constant which can be calculated as $p_{c h}=C / T_{c h}$ (including the charging efficiency). A battery can be divided into

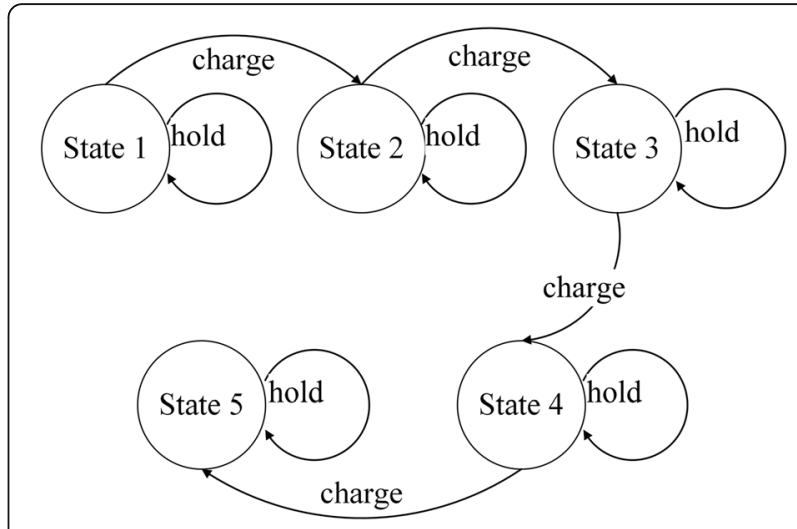

Fig. 2 State flow chart for EV battery

$T_{c h}$ states numbered as $1,2,3, \ldots \ldots, T_{c h}-1, T_{c h}$, according to the SOC of batteries.

With the charging process, the state of the battery changes. The state flow is shown in Fig. 2 when $T_{c h}$ is 5 . While being in charge, the state would transfer from state 1 to state 5 constantly, until reaching state 5 , means fully charged in this example. The state would continue to be same while in idle state.

\section{Methods}

\subsection{Objective function}

The planning model objective for a BSS is to maximize the net profit for providing battery swapping services, which can be calculated by income, fixed cost and variable cost. The income includes the swapping service fees. The fixed cost includes the expenses to allocate facilities like batteries, chargers and swapping robots. The variable cost includes the energy charge paid for the electricity which is used to charge batteries mainly, these electricity can come from power system or the PV supplier.

Due to the uncertainties of future EV swapping demands and output abilities of PV energy, a set of potential future planning scenarios $(\Omega)$ should be forecasted and established to ensure the availability and flexibility of planning model strategy.

The aim of BSS is trying to maximize the annual profit. So the objective function is formulated as follows:

$$
\operatorname{Max} f=\operatorname{Max}\left\{365 \cdot \frac{\sum_{\omega \in \Omega}\left(R-C_{\text {variable }}\right)}{N_{\Omega}}-C_{\text {fixed }}^{\text {year }}\right\}
$$

The first term in objective function is the total annual equivalent operation profit under different stochastic scenarios and the second term is the annual equivalent investment cost. 
Where $R$ is the daily income during the specific operation period, $C_{\text {variavle }}$ is the daily variable cost such as operation cost to purchase energy and $C_{\text {fixed }}^{\text {year }}$ is the annual fixed cost of BSS such as investment cost.

The annual fixed cost can be calculated as follows:

$$
\mathrm{C}_{\text {fixed }}^{\text {year }}=\mathrm{n}^{s} \cdot c^{\text {barttry }}+n^{\text {charge }} \cdot c^{\text {charge }}+\mathrm{n}^{\text {robot }} \cdot c^{\text {robot }}
$$

Where $n^{s}$ is the total number of batteries stored in BSS, $c^{\text {barttery }}$ is the annual fixed cost for an EV battery, $n^{\text {charge }}$ is the number of chargers in BSS, $c^{\text {charge }}$ is the annual fixed cost for a charger, $n^{\text {robot }}$ is the number of swapping robots in BSS and $c^{\text {robot }}$ is the annual fixed cost for a swapping robot. The annual fixed cost for a battery, a charger and a swapping station can be calculated with formula (1) separately.

The daily income during operation period is as follows:

$$
R=\sum_{t=1}^{T} n_{t}^{d} \cdot c^{\text {service }}
$$

Where $c^{\text {service }}$ is the service fee BSS charges for supplying the swapping service.

The daily operation cost can be formulated as follows:

$$
\mathrm{C}_{\mathrm{variable}}=\sum_{t=1}^{T}\left(P_{t}^{\text {sys }} \cdot c_{t}+P_{t}^{s} \cdot c^{\text {solar }}\right)
$$

Where $P_{t}^{s y s}$ is the power purchased from the system at time $t$, and $c_{t}$ is the system electricity price at time $t, P_{t}^{s}$ is the power purchased from PV supplier at time $t$, and $c^{\text {solar }}$ is the price of solar energy.

\subsection{Constrain conditions}

Since future EV swapping demand and PV output are both uncertain. Swapping demand can be influenced by various stochastic factors such as work/weekend days, personal travel arrangements, etc. [19]. PV output can be influenced by weather conditions especially solar radiation intensity. Therefore, operation simulation procedure is necessary under enough scenarios and following constrain conditions need to be satisfied under each operation scenario.

\section{1) Swapping demand balance}

Typically, EVs battery can be replaced at once if there are full charged batteries. If not, the EVs will wait into the queue until there is a battery ready for swapping.

$$
n_{t}^{\text {service }}+n_{t}^{\text {wait }}=n_{t}^{d}
$$

Where $n_{t}^{\text {service }}$ is the number of EVs whose battery can be replaces at time $t, n_{t}^{\text {wait }}$ is the number of EVs that should be taken into the queue. It means EVs get into the queue when it is positive, and get out of the queue when it is negative.

2) Number of EV batteries constraint

The number of batteries at different states in BSS is equal to the total number of batteries stored in BSS.

$$
\sum_{i}^{T_{c h}}\left(n_{t}^{i}+n_{t}^{i 0}\right)+n_{t}^{s}=n^{s}
$$

Where $n_{t}^{i}$ is the number of charging batteries at state $i$ at time $t, n_{t}^{i 0}$ is the number of idled batteries at state $i$ at time $t$.

3) Number of EV batteries at each state equation constraint

The following constraint should be satisfied during the swapping process:

$$
n_{t}^{d i}+n_{t}^{d i 0}+n_{t}^{w i}=n d_{t}^{i}
$$

Where $n_{t}^{d i}$ is the number of batteries in charging at state $i$ replaced from EVs at time $t, n_{t}^{d i 0}$ is the number of idle batteries at state $i$ replaced from EVs at time $t, n_{t}^{w i}$ is the number of batteries at state $i$ that enter into or quit from the queue, $n d_{t}^{i}$ is the number of batteries at state $i$ in the swapping demand.

4) Waiting queue length constraint

The length queue at any time can be calculated as follows:

$$
\begin{aligned}
& n_{t}^{\text {queue }}=\left\{\begin{array}{cc}
n_{t-1}^{\text {queue }}+n_{t}^{\text {wait }} & (2 \leq t \leq T) \\
0+n_{t}^{\text {wait }} & (t=1)
\end{array}\right. \\
& n_{t}^{q i}=\left\{\begin{array}{cc}
n_{t-1}^{q i}+n_{t}^{\text {wi }} & (2 \leq t \leq T) \\
0+n_{t}^{\text {wi }} & (t=1)
\end{array}\right.
\end{aligned}
$$

Where $n_{t}^{\text {queue }}$ is the number of EVs waiting in the queue at time $t, n_{t}^{q i}$ is the number of batteries at state $i$ in the EVs waiting in the queue at time $t$.

5) Number of swapped EV batteries into storage constraint 
The number of batteries at state $i$ in swapping demand is equals to the number of batteries at state $i$ and will be in charging at next time interval replaced from EVs plus the number of batteries at state $i$ and will be in idle at next time interval replaced from EVs.

$$
\sum_{i=1}^{T_{c h}}\left(n_{t}^{d i}+n_{t}^{d i 0}\right)=n_{t}^{\text {service }}
$$

6) Number of batteries in charging constraint

Anytime, the number of batteries in charging should be less than the number of chargers.

$$
\sum_{i=1}^{T_{c h}} n_{t}^{i}+n_{t}^{d i} \leq n^{\text {charge }}
$$

7) Number of charging batteries at different state constraint

The number of batteries in charging at state $i$ can be calculated as follows:

$$
n_{t}^{i}=n_{t-1}^{i-1}+n_{t-1}^{d i-1}+\mathrm{nt}_{t-1}^{i 0} \quad(2 \leq t \leq T)
$$

Where $\mathrm{nt}_{t-1}^{i 0}$ is the number of batteries at state $i$ which is in idle at time $t-1$ and will be in charging at time $t$.

8) The number of idle batteries constraint

The number of batteries in idle at state $i$ can be calculated as follows:

$$
n_{t}^{i 0}=n_{t-1}^{i 0}+n_{t-1}^{d i 0}-\mathrm{nt}_{t-1}^{i 0} \quad(2 \leq t \leq T)
$$

9) The number of full charged batteries constraint

The number of full charged batteries can be calculated as follows:

$$
n_{t}^{s}=n_{t-1}^{s}+n_{t-1}^{T_{c h}}+n_{t-1}^{d T_{c h}}-n_{t-1}^{\text {service }} \quad(2 \leq t \leq T)
$$

Where $n_{t}^{s}$ is the number of full charged EV batteries at time $t$.

10) EV battery start and end time state balance

The SOC and the states of EV batteries at the end of the day should be the same as it was at the beginning of the day for the cycling operation pattern of BSS.

$$
\begin{aligned}
& n_{1}^{s}=n_{T}^{s} \\
& n_{1}^{i}=n_{T}^{i} \\
& n_{1}^{i 0}=n_{T}^{i 0}
\end{aligned}
$$

\section{1) Power balance constraint}

The power purchased from the PV electricity supplier plus that one purchased from the grid should equal to the charging power EV batteries need.

$$
P_{t}^{s}+P_{t}^{s y s}=P_{t}
$$

Where $P_{t}$ is the charging power at time $t$.

12) PV output constraint

The power purchased from the PV electricity supplier should not be greater than the power PV electricity supplier generates.

$$
P_{t}^{s} \leq P_{t}^{\text {solar }}
$$

Where $P_{t}^{\text {solar }}$ is the output of PV energy at time $t$.

13) Maximum service ability constraint

The ability BSS can serve at one time interval is influenced by both the number of EV batteries fully charged and the number of swapping robots. And the constraint below should be satisfied.

$$
\mathrm{n}_{t}^{\text {service }} \leq \min \left(n_{t}^{s},\left[t_{\text {unit }} / t_{\text {change }}\right] \cdot n^{\text {robot }}\right)
$$

Where $n^{\text {robot }}$ is the number of swapping robots in BSS, $t_{\text {unit }}$ is the time interval in the research, $t_{\text {change }}$ is the time to swap for each EV, [ ] is the rounding operator.

14) Variables constraints

Some decision variables of the model proposed should meet constrains such as follows:

$$
\begin{aligned}
& n_{t}^{i}, n_{t}^{i 0}, n_{t}^{d i}, n_{t}^{d i 0}, \mathrm{n}^{s}, n^{\text {charge }}, \mathrm{n}^{\text {robot }}, \\
& \mathrm{n}^{\text {solar }}, n_{t}^{\text {service }}, n_{t}^{\text {queue }}, n_{t}^{\text {wi }} \in N \\
& n_{t}^{\text {wait }}, n_{t}^{q i} \in \mathrm{Z}
\end{aligned}
$$

15) PV consumption bundling constraint 
BSS needs to consume a certain amount of PV output in a certain time period like a month or a year from bundling PV seller.

$$
\sum_{\omega \in \Omega} \sum_{t=1}^{T} P_{t}^{s} \geq c a p^{\text {solar }} \cdot \sum_{\omega \in \Omega} \sum_{t=1}^{T} P_{t}^{\text {solar }}
$$

Where cap $^{\text {solar }}$ is the PV consumption percentage requirement BSS needs to be satisfied.

\section{6) Customer satisfaction}

The probability that customer satisfaction meet the specific level is allowable in reality but should reach an acceptable level. As mentioned in 2.4, four customer satisfaction indexes are set up to the threshold, including maximum queue length $L_{\max }$, average queue length $\bar{L}$, normalized average queue length for each swapping demand $\overline{\mathrm{L}_{\text {unit }}}$, and probability $P_{\eta}$ of queue length longer than some value, see formula (2), (3), (4) and (5).

The above operation condition can be expressed as deterministic and chance constraints as follows:

$$
\begin{aligned}
& L_{\max } \leq \alpha \\
& \bar{L} \leq \beta \\
& \overline{L_{\text {unit }} \leq \delta} \\
& P_{\eta} \leq \varepsilon
\end{aligned}
$$

Where $\alpha, \beta, \delta, \varepsilon$ are the parameters set to meet the expected customer satisfaction requirement.

\section{Case study and Results}

\subsection{Basic stats}

This study assesses the individual effect of PV output uncertainty and swapping demand uncertainty. Some critical factors have great influence on battery swapping demand level [24], but it is out of the scope of this paper. We assume that the battery swapping demand is under well forecasting [25]. The typical battery swapping demand curves on workdays, weekends and in festival days are shown in Fig. 3 [26], and the probability for above three typical demand curves are $68.4 \%, 23.6 \%$ and $8.0 \%$. The total daily demand number is around 600 . There are two swapping demand peaks on workdays and weekends. In festivals, the swapping demand is concentrated and large during the day time. It is assumed that the energy state-of-charges (SOCs) of EVs that come to BSS for battery swapping service are uniformly randomized between state 2 to state 4 [7], and the total daily energy refueling demand is around $7,500 \mathrm{kWh}$. The replaced EV batteries will be placed in the storage and fully recharged at a specific time to be available for other EVs. And we assume that only the fully charged EV batteries can be used for swapping.

Typical daily output curves of PV in different seasons are as shown in Fig. 4, which are the typical outputs in Spring, Summer, Autumn, and Winter when sunshine condition is good, and the probability for each seasonal typical outputs are all 25\%. It is noted that the short-term fluctuations for both swapping demand and PV output are also taken into account in our study. System parameter values are depicted in Table 1, which are based on the data from open channels or some inquiries. As a main facility in BSS, EV battery accounts for a large part of the cost of one electric vehicle. The key problem while operating BSS is to use and maintenance batteries properly. One simple method is to prevent charging and discharging frequently so as to reduce the number of switching state of the batteries [27], and we assume that the charging process is continuous without interruption. Now China is under the initial

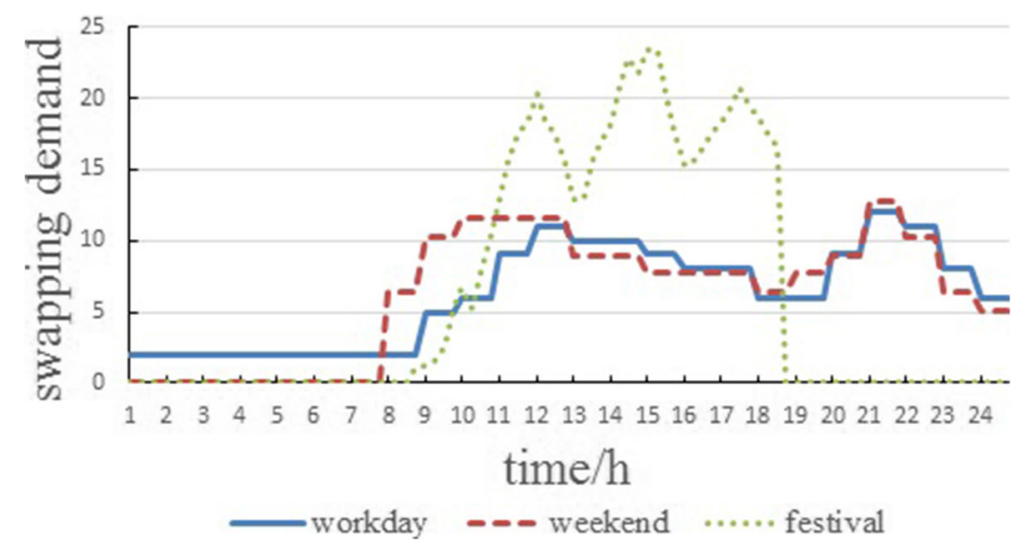

Fig. 3 Typical battery swapping demand curves on workdays, weekends and in festival days 


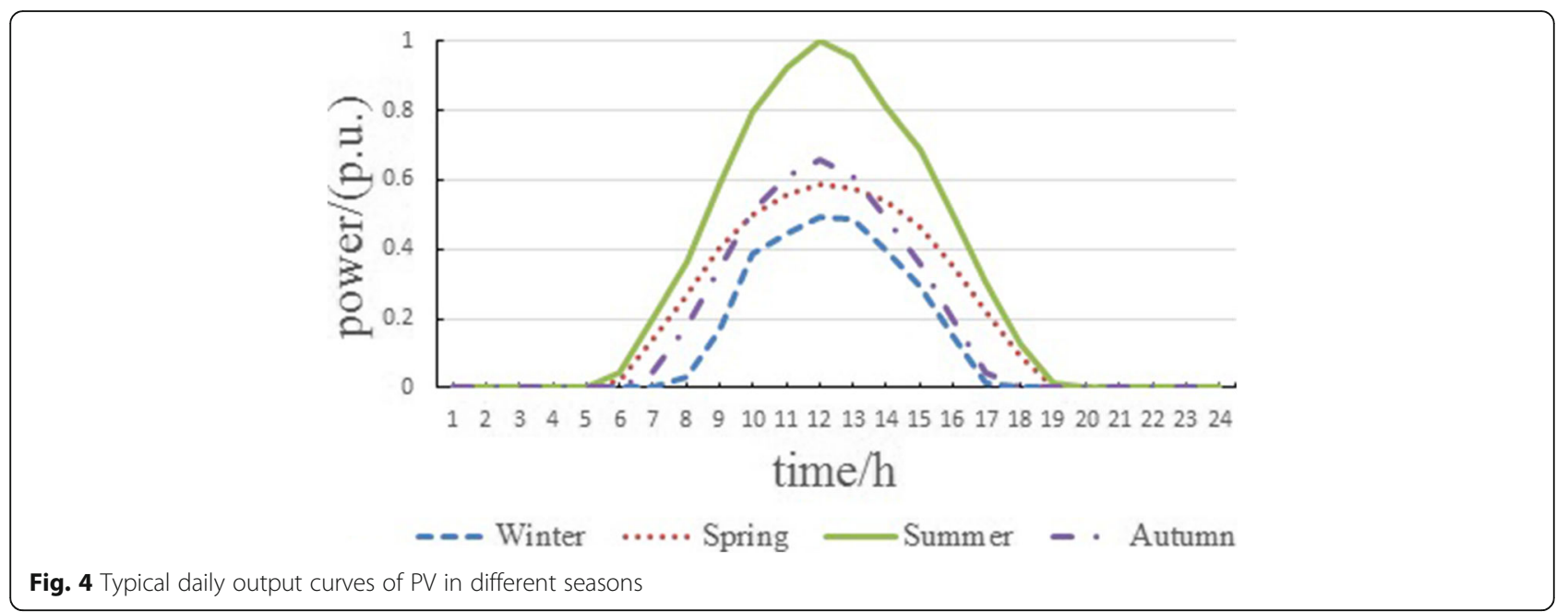

stage of establishing competitive electrical market, real time price mechanism is not yet implemented, and it will need a long time to be perfect. It should be noted that time-of-use price mechanism and related practices were carried out in most cities of China, some experience has been accumulated, so TOU mechanism is adopted in the case study. TOU reflects peak and valley conditions of power system, which encourages EV BSS to make contribution to relieve system pressure. Assuming that the BSS is treated as industry/commerce customer connected to $10 \mathrm{kV}$ distribution network, the electricity price for this kind of electricity customer references to the TOU of Beijing city in China and is provided in Table 2 . The daily research period is $24 \mathrm{~h}$, each time interval is $15 \mathrm{~min}$. Customer satisfaction index threshold $\alpha=6, \beta=0.25, \delta=0.25, \eta=3$ and the related probability level $\varepsilon$ is $10 \%$ respectively. The PV consumption percentage requirement $c a p^{\text {solar }}=80 \%$. Considering that the correlation between PV output uncertainty and swapping demand uncertainty is low, the probability of combined scenarios can be calculated individually. The results of our proposed model are compared with the model without PV consumption bundling. The collaborative optimization configuration and operation decision for BSS in one day can be solved. The model is a mixed-integer linear programming (MILP) model implemented in GAMS 24.4.0 and solved using CPLEX.

\subsection{Results}

The optimal configuration solutions under scenarios with and without PV bundling are displayed and compared in Table 3. The total energy consumption are

Table 1 Values of system parameters

\begin{tabular}{lll}
\hline No. & Parameter & Value \\
\hline 1 & PV installed capacity/(kW) & 1,000 \\
2 & PV energy price/(yuan/kWh) & 0.65 \\
3 & Battery capacity/(kWh) & 20 \\
4 & Charging power/(kW) & 10 \\
5 & Charging efficiency/(\%) & 88 \\
6 & Swapping service fee/(yuan) & 25 \\
7 & Cost for EV battery/(yuan/each) & 83,000 \\
8 & Cost for charging charger/(yuan/each) & 6,000 \\
9 & Cost for swapping robot/(yuan/each) & 160,000 \\
10 & Robot swapping capability/(service times/each time interval) & 4 \\
11 & Life time of each facility/(year) & 5 \\
\hline
\end{tabular}


Table 2 Time-of-use price

\begin{tabular}{llc}
\hline Levels & Time period & Price/(yuan/kWh) \\
\hline Peak time & 10:00-15:00, 18:00-21:00 & 1.3782 \\
Mean time & 7:00-10:00, 15:00-18:00, & 0.8595 \\
Valley time & 21:00-23:00 & \\
\hline
\end{tabular}

Table 3 The optimal configuration solutions under scenarios with and without PV bundling

\begin{tabular}{lllll}
\hline PV bundling/(\%) & $\begin{array}{l}\text { Number of } \\
\text { robots }\end{array}$ & $\begin{array}{l}\text { Number of } \\
\text { batteries }\end{array}$ & $\begin{array}{l}\text { Number of } \\
\text { chargers }\end{array}$ & $\begin{array}{l}\text { Profit/ } \\
\text { (yuan) }\end{array}$ \\
\hline $\begin{array}{l}\text { Without PV } \\
\text { bundling (0\%) }\end{array}$ & 6 & 101 & 125 & $573,679.7$ \\
$\begin{array}{l}\text { With PV } \\
\text { bundling (90\%) }\end{array}$ & 6 & 101 & 125 & $520,679.7$ \\
\hline
\end{tabular}

different under scenarios with and without PV bundling, the gap is due to the difference of optimal solutions for battery SOC at initial and end period. The little gap does not affect the validity of our research. The annual profit under scenario with PV bundling is less than ones under scenario without PV bundling, because PV consumption bundling requirement sacrifices the operation flexibility of BSS and makes annual profit lower than optimal strategy without bundling. In addition, more PV electricity consumption can get more environmental benefit, but that has not been included into our model yet. The robot configuration number are same for these 2 scenarios, because the swapping demand level at one time interval is the key impact on deciding how many swapping robots are necessary.

The charging power curves are displayed in Fig. 5. Under scenario without PV bundling, the charging power curve is much smooth than the curve under scenario with PV bundling. The charging power at mean time (such as 15:00-18:00) and peak time period (such as 18:00-21:00) is not low enough because it is more economic to pay for high electricity price than configuring more EV batteries to improve its flexibility. BSS needs to absorb PV energy at a certain period due to PV only generates energy at a given period (around 7:0019:00 in Summer), this sacrifices the profit level.

In the meantime, we could find that the charging power from late night to early morning is still at a high level under scenario without PV bundling. Coincidently, the output of wind power is large in this time period coincidently according to many research reports. This indicates that the BSS also has the potential to absorb wind power.

The customer waiting queue lengths are depicted in Fig. 6. Under both scenarios with and without PV bundling, EVs have to wait in the queue during the second swapping demand peak time at workdays. The queue is due to BSS can charge batteries during mean and valley time price period when second swapping demand peak comes to save electricity payment. But the queue problem can be solved by setting a suitable customer satisfaction levels.

The PV consumption curves are shown in Fig. 7. The BSS consumes 90\% energy as PV output (capacity: $1,000 \mathrm{~kW}$ ) under scenario with PV consumption bundling requirement, that is the majority of power that PV generates. It is noteworthy that BSS indeed has the potential to absorb PV energy in this condition.

The redundancy of the batteries are shown in Fig. 8. It appears that BSS charges the most of batteries in the off-peak time of power system and stores them for the following swapping peak demand especially under scenarios without PV bundling. The number of fully charged batteries declines rapidly as swapping demand rises.

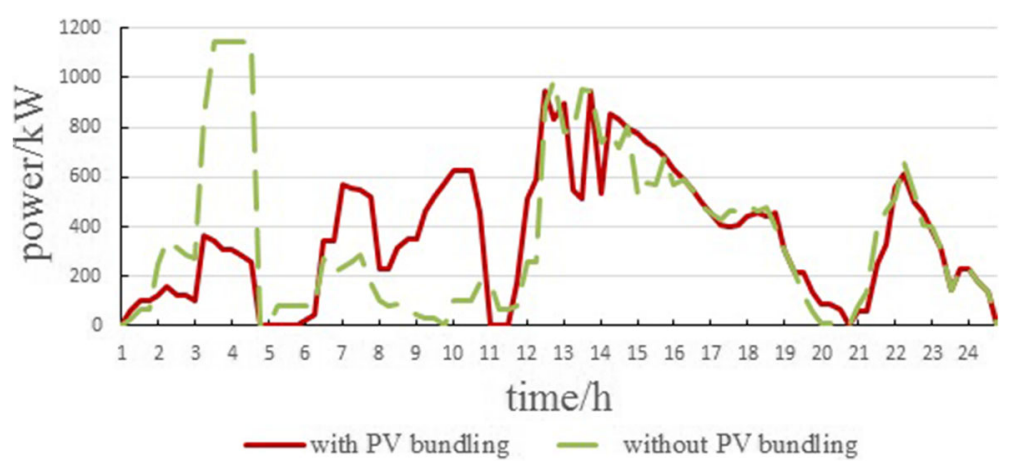

Fig. 5 Charging power curves with and without PV bundling requirements at a workday in Summer 




Fig. 6 Waiting queue lengths with and without PV bundling requirements at a workday in the Summer

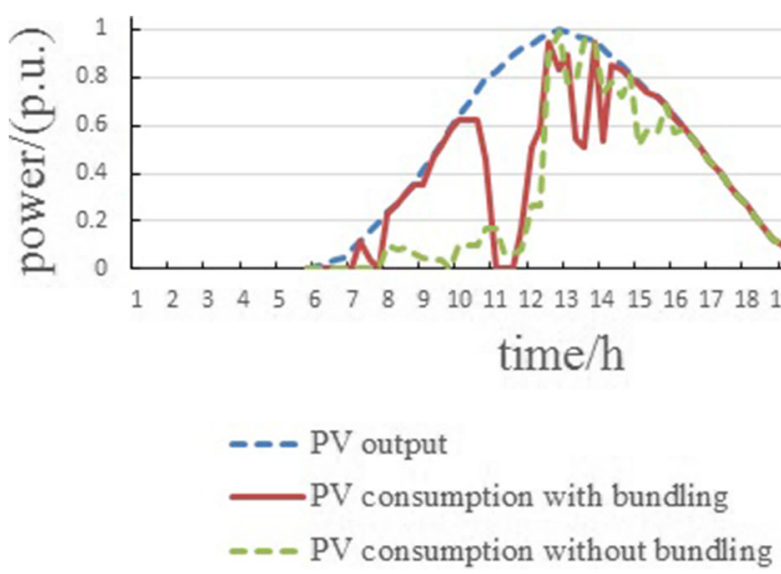

Fig. 7 PV consumption curves with and without PV bundling requirements at a workday in the Summer

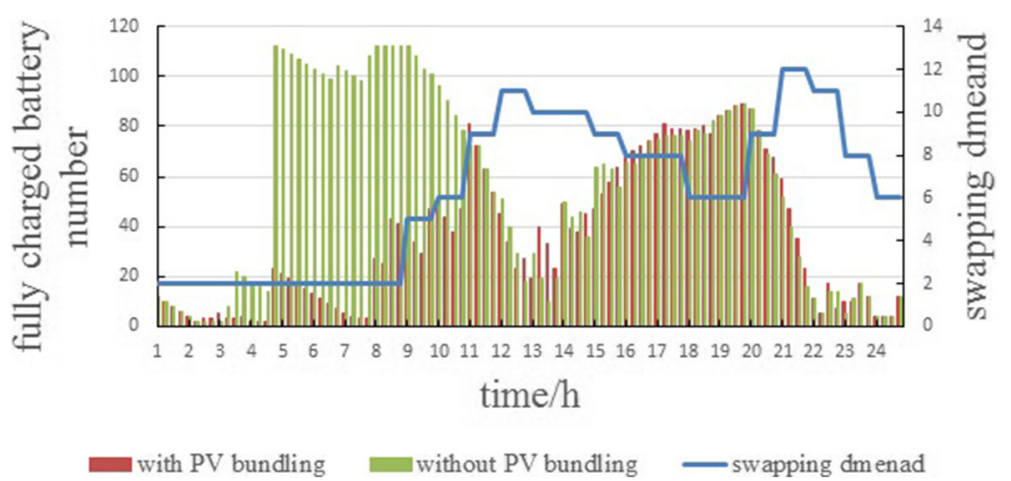

Fig. 8 EV battery redundancy curves with and without PV bundling requirements at a workday in the Summer

\section{Discussions}

EV BSS is the participator in both electricity system and traffic system, the decision of BSS is influenced by conditions in both two systems. The sensitive analysis is proposed from the aspects of economy and technology.
5.1 Impact analysis to BSS demand response capability with different BSS configuration structures

BSS has two demand response capabilities, one is to respond system TOU price for peak shaving and valley filling, and the other is to consume clean energy 
that PV or wind power generates. The former is beneficial to power system operation and the latter is environmental. The EVs number coming to refuel is fixed for a specific BSS, which determines daily energy demand. So there is a trade-off between system TOU price response capability and clean energy consumption response capability.

The investment cost accounts for a relatively large expenditure during the life cycle of BSS. Considering the costs for each battery, charger are likely to reduce in the following five years. The impact of this reduction will be discussed in this part. We do not include the swapping robot into discussion because the determinants for BSS to increase the number of robots are the swapping demand level and customer satisfaction level. At the same time, considering that the cost for a battery is much more expensive than the cost for a charger, so only the cost of each battery is selected into discussion here. The charging power curves, system charging curves and PV consumption power curves with different costs of each battery are depicted in Figs. 9, 10, 11 and the optimal configurations and energy consumptions of BSS are shown in Table 4.

It can be concluded that with the cost of each battery decreases, BSS reschedule the charging arrangement. The charging power is high at valley time period and small at peak time period. The effect of peak shaving and valley filling becomes obvious when battery cost is less than 45,000 . While the battery cost is 15,000 , the number of batteries and chargers change from 125 and 183 (scenario with 83,000 yuan for each battery) to 101 and 73 , which resulting in the great improvement of capability for BSS as demand response resource to response the TOU.

It can be concluded that with the decline rate of battery's price increases, BSS reschedule the charging arrangement. The charging power is high at mean time period and small at peak time period. The effect of peak
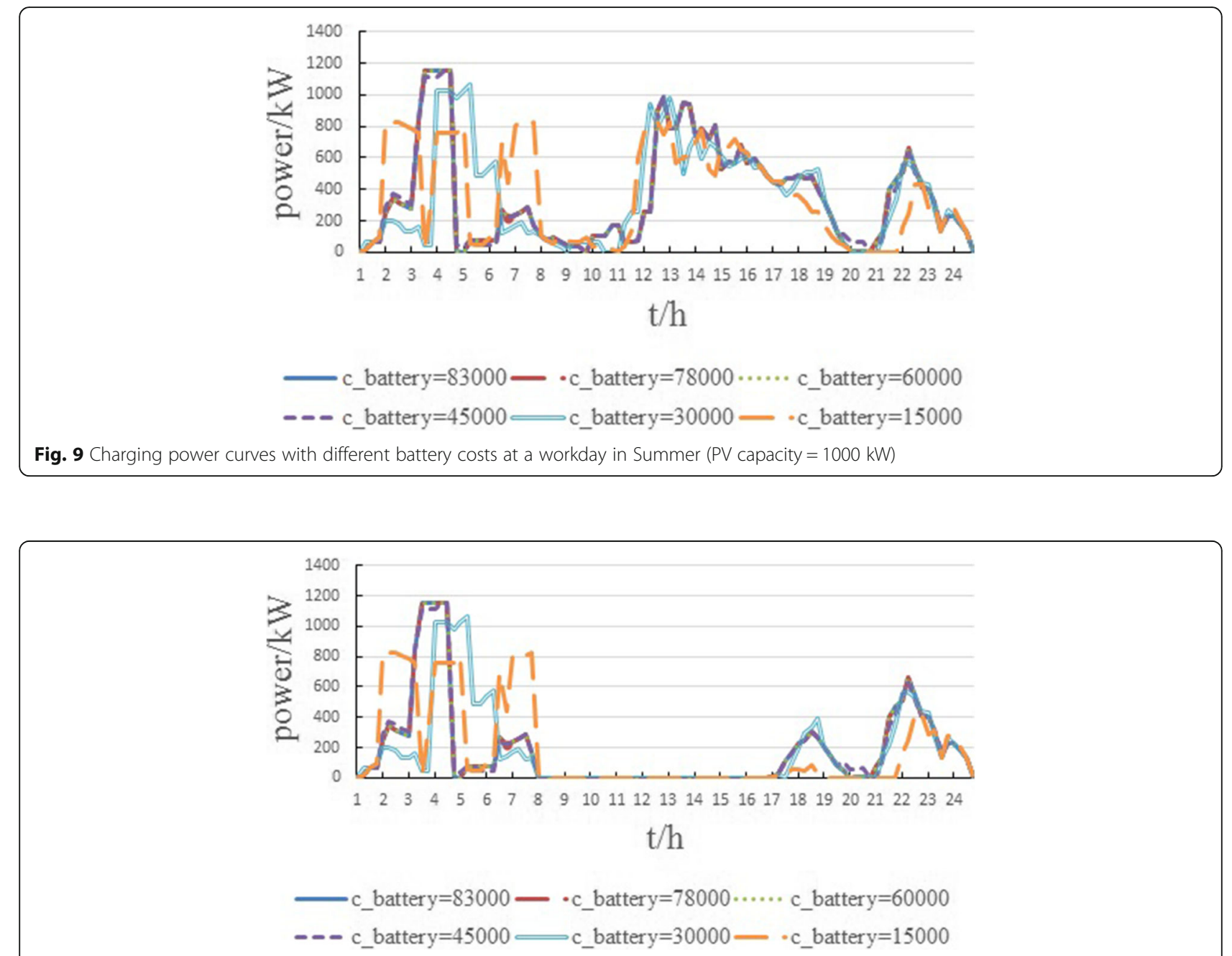

Fig. 10 System charging power curves with different battery costs at a workday in Summer (PV capacity = $1000 \mathrm{~kW}$ ) 


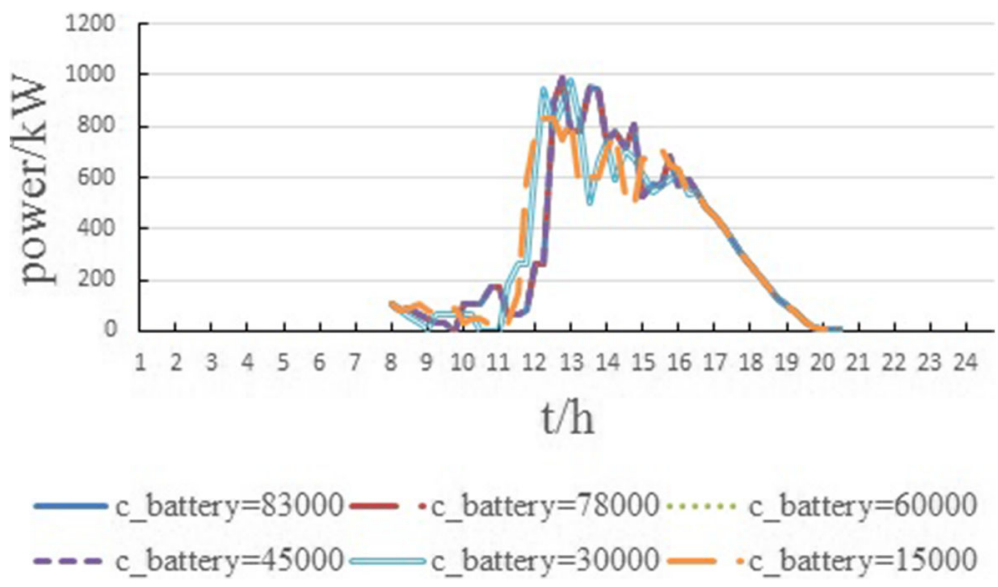

Fig. 11 PV consumption power curves with different battery costs at a workday in Summer (PV capacity $=1000 \mathrm{~kW}$ )

Table 4 The optimal configurations and energy consumptions of BSS with different costs of battery

\begin{tabular}{|c|c|c|c|c|c|c|}
\hline Battery cost/(yuan/each) & 83,000 & 78,000 & 60,000 & 45,000 & 30,000 & 15,000 \\
\hline Number of robots & 6 & 6 & 6 & 6 & 6 & 3 \\
\hline Number of batteries & 125 & 125 & 125 & 125 & 132 & 183 \\
\hline Number of chargers & 101 & 101 & 101 & 101 & 94 & 73 \\
\hline Valley time energy/(kWh) & $2,653.295$ & $2,653.295$ & $2,653.295$ & $2,653.409$ & $2,752.841$ & $3,636.364$ \\
\hline Mean time energy/(kWh) & $1,140.711$ & $1,140.711$ & $1,140.711$ & $1,140.711$ & $1,140.597$ & 646.3928 \\
\hline Peak time energy/(kWh) & 392.5868 & 392.5868 & 392.5868 & 392.5873 & 293.155 & 1.6445 \\
\hline Solar energy/(kWh) & 4,330.339 & 4,330.339 & 4,330.339 & $4,330.339$ & $4,330.089$ & $4,330.339$ \\
\hline Profit/(yuan) & $573,679.7$ & $756,179.7$ & $1,212,430$ & $1,668,283$ & $2,131,929$ & $2,674,645$ \\
\hline
\end{tabular}

shaving becomes obvious when decline rate is more than $50 \%$. While the decline rate reaches $81 \%$, the number of batteries and chargers are improved from 72 and 50 (base scenario) to 132 and 76, which resulting in the great improvement of ability for BSS as demand response resource to response the TOU and the load peak of charging power is also decreases.

\subsection{Impact analysis of different PV capacity and consumption bundling requirement combinations}

The emission advantage for EVs is not obvious while the charging power is supplied by coal-fired power plants primarily [7]. The environmental benefit of BSS is focus of study. Analysis of optimal results has indicated BSS indeed has a good quality potential to absorb PV energy while finishing the consumption bundling contract. Fig. 12 shows the annual profit surfaces with different PV capacities and bundling requirements. The annual profit value decreases rapidly when PV bundling requirement and PV capacity increase. The boundary curve between green and red areas at the bottom left of the picture shows the combinations of PV bundling requirements and PV capacities making annual profit of
BSS equals to zero. This curve is an extreme trade-off between PV bundling requirements and PV capacities due to the BSS surrenders all of its profit level to finish PV consumption contract. The surface throws out suggestions for BSS how to sign contract with PV sellers to get specific profit value.

Profit value curves with different PV bundling requirements are depicted in Fig. 13. It is more visualized than Fig. 12. The points whose profits equal to zero is defined as the limitation capability for BSS to accomplish PV consumption task. For instance, the 90\% consumption contract with a $1,500 \mathrm{~kW}$ capacity PV seller is equivalent to the $95 \%$ consumption contract with an around 1,300 kW capacity PV seller. It can be concluded that as PV capacity increases from a low level, the profit value increases and gets a best profit point and then decreases rapidly under scenarios with higher bundling requirements. And the lower the bundling requirement is, the more capacity agreement the BSS can reach with the PV seller.

Considering the profit value curves under different PV bundling requirements which are less than $80 \%$. There is an interesting discovery. The profit curves are inverted U-shaped. There is an optimum point for BSS to get 


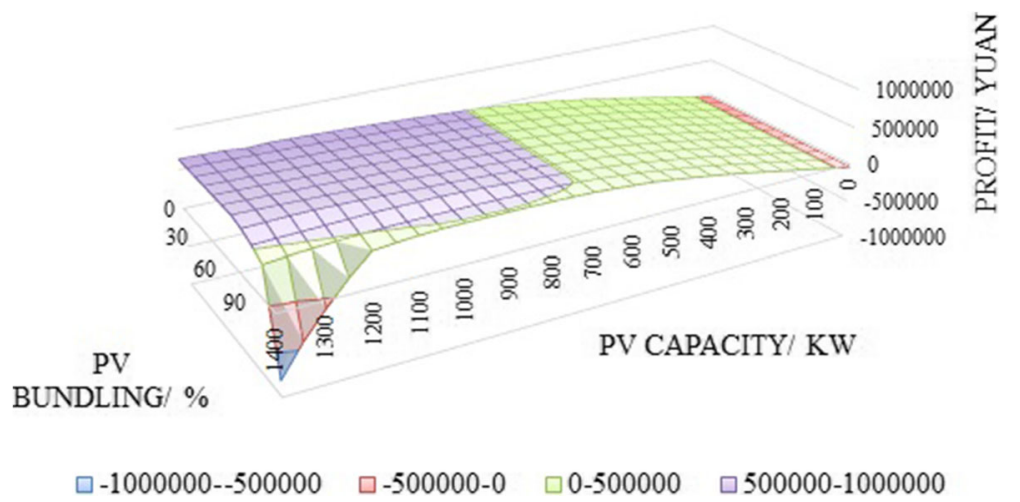

Fig. 12 Profit value surface with different PV capacities and bundling requirements

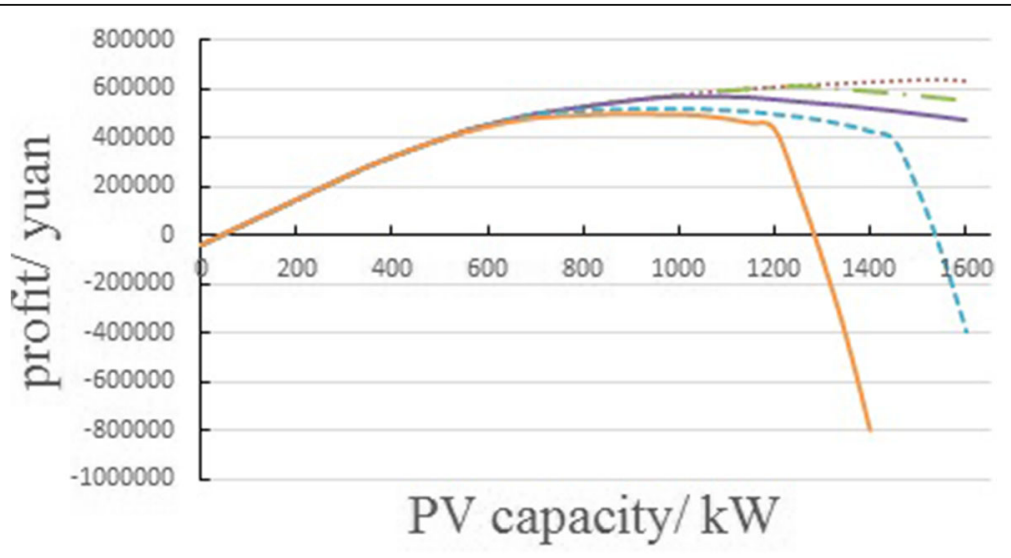

…..... $0-60 \%-70 \%-70 \%---90 \%-95 \%$

Fig. 13 Profit value curves with different PV bundling requirements

maximal profit value under a certain bundling requirement. As PV capacity increases, the profit value rises at first. And then when the capacity exceeds a certain value, the profit falls as shown in Fig. 13. This discovery indicates there is a natural incentive for the BSS serving a specific amount of swapping demand to consume and absorb a certain amount of PV energy if the price is appropriate. In contrast, the profit levels for BSS will be reduced under excessive PV consumption bundling requirements.

It is attractive that the profit value rises at first and then falls. Table 5 shows the optimal configuration solutions of BSS with different PV capacities when PV consumption bundling requirement is set as $80 \%$. With a fixed bundling requirement, there is no a strict linear pattern of optimal configuration solutions of batteries and chargers as PV capacity increases. It is concluded that BSS overall needs more chargers and then needs more batteries with PV capacity increasing. This phenomenon is much more obvious when capacity is more than $1,200 \mathrm{~kW}$. The annual profit value increases from $146,640.2$ yuan to $568,871.9$ yuan when capacity increases from $200 \mathrm{~kW}$ to $1,000 \mathrm{~kW}$, and then the annual profit decreases to $471,516.5$ yuan when capacity

Table 5 The optimal configuration solutions of BSS with different PV capacities (PV bundling requirement $=80 \%$ )

\begin{tabular}{lllllllll}
\hline PV capacity/(kW) & 200 & 400 & 600 & 800 & 1,000 & 1,200 & 1,400 & 1,600 \\
\hline Number of robots & 6 & 6 & 6 & 6 & 6 & 6 & 6 & 6 \\
Number of batteries & 125 & 125 & 125 & 125 & 125 & 125 & 167 & 249 \\
Number of chargers & 102 & 102 & 102 & 102 & 101 & 101 & 77 & 87 \\
Profit/(yuan) & $146,640.2$ & $322,671.8$ & $452,113.7$ & $526,964.5$ & $568,871.9$ & $556,351.1$ & $519,923.2$ & $471,516.5$ \\
\hline
\end{tabular}




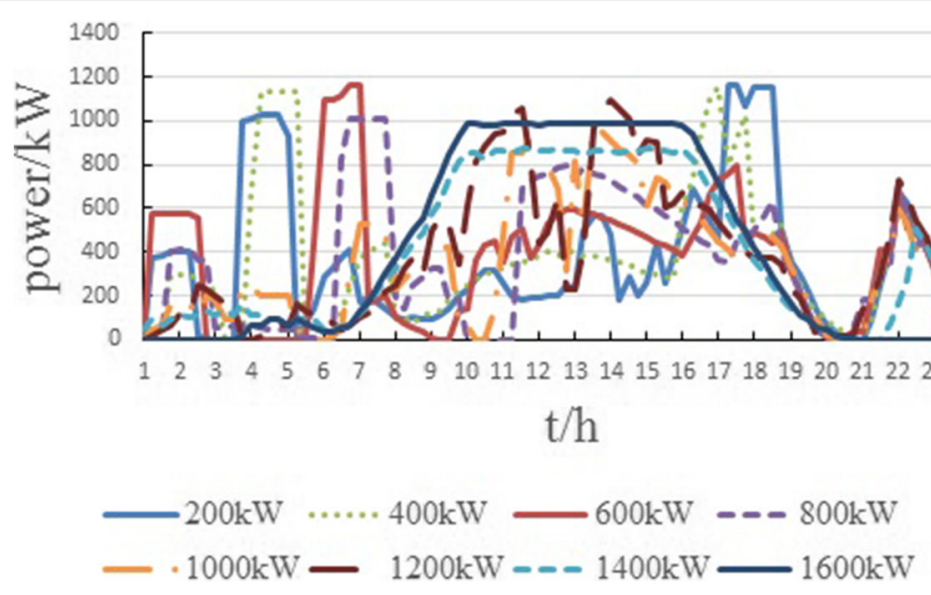

Fig. 14 Charging power curves with different PV capacities (PV bundling requirement $=80 \%$ )

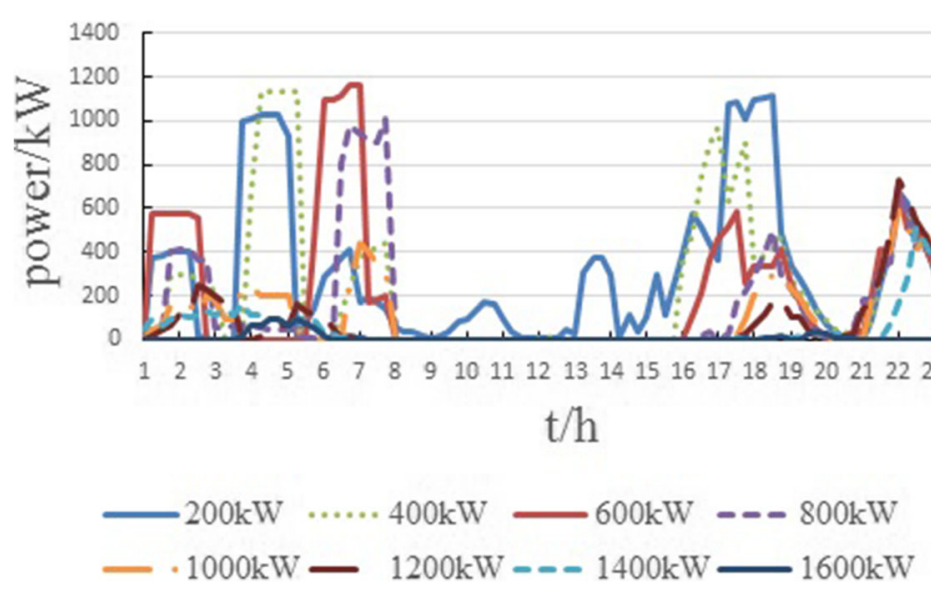

Fig. 15 System charging power curves with different PV capacities (PV bundling requirement $=80 \%$ )

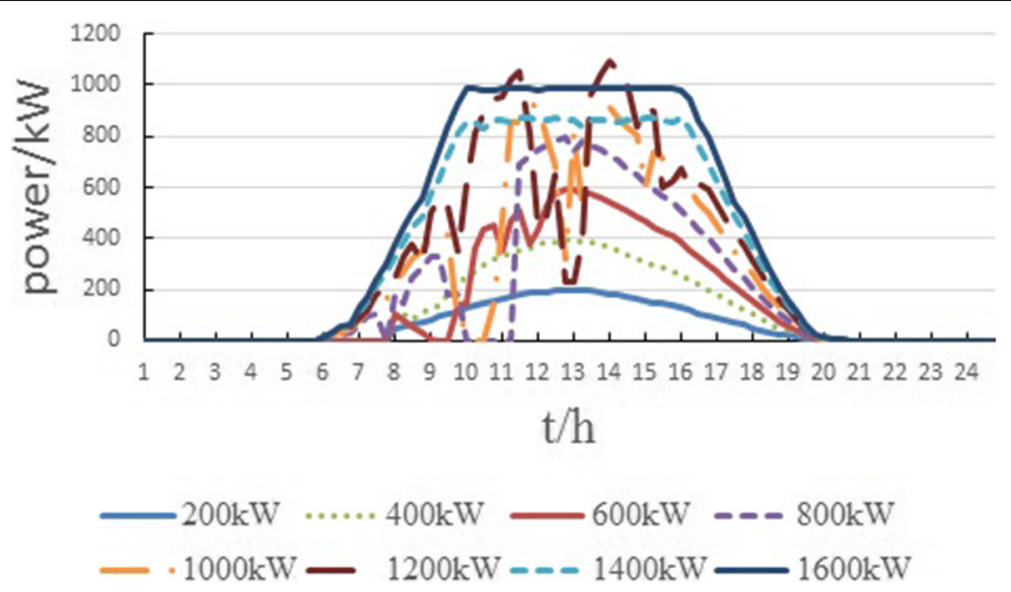

Fig. 16 PV consumption curves with different PV capacities (PV bundling requirement $=80 \%$ ) 
Table 6 The energy consumption distribution of BSS with different PV capacities (PV bundling requirement $=80 \%$ )

\begin{tabular}{lllllllll}
\hline PV capacity/(kW) & 200 & 400 & 600 & 800 & 1,000 & 1,200 & 1,400 & 1,600 \\
\hline Valley time energy/(kWh) & $2,715.909$ & $2,659.092$ & $2,653.409$ & $2,179.297$ & $1,233.234$ & 665.1525 & 676.2998 & 165.8008 \\
Mean time energy/(kWh) & $3,320.774$ & $2,642.929$ & $1,780.901$ & $1,291.263$ & $1,095.473$ & 966.705 & 618.705 & 12.747 \\
Peak time energy/(kWh) & $1,085.139$ & 436.8878 & 418.9328 & 405.8543 & 393.9313 & 360.3088 & 55.30375 & 28.80975 \\
Solar energy/(kWh) & $1,426.474$ & $2,780.979$ & $3,663.803$ & $4,671.89$ & $5,839.863$ & $7,007.833$ & $8,175.805$ & $9,343.777$ \\
\hline
\end{tabular}

continues to increase to $1,600 \mathrm{~kW}$. It is indicated that the optimal PV consumption capability for BSS is around $1,000 \mathrm{~kW}$ when requirement is $80 \%$, which can be confirmed in Fig. 13. The numbers of robots are changeless under different scenarios, because the number of swapping robots is influenced by swapping demand at a specific period mainly as mentioned earlier. In our case study, the maximal swapping demand is 23 , which can be refueled by 6 robots once at each time interval.

The charging power curves, system charging power curves and PV consumption curves with different PV capacities are shown in Figs. 14 15, 16. Table 6 displays the energy consumption distribution of BSS with different PV capacities. The power curves vary under different scenarios, that means BSS is capable of different operation mode to adapt to external environment and incentive signals. As the PV capacity increases, BSS consumes less and less energy from system at peak time period. The energy consumption from system also decreases because BSS needs to accomplish the PV consumption bundling requirement. It can be concluded that BSS indeed has capability to achieve peak shaving even without sacrificing much profit level when incentives are appropriate.

\subsection{Impact analysis of configuration considering multi- swapping demand scenarios and single swapping demand scenario}

There are many uncertainties in BSS operation external environment such as PV outputs and EVs swapping demands, et.al. The difference of optimal configurations between considering multi-swapping demand scenarios and only single typical daily swapping demand are compared in this section. The different solutions are displayed and compared in Table 7.

It can be concluded that the configuration number of robots, batteries and chargers are all larger under multiswapping demand scenarios and the annual profit when considering multi-scenarios is lower compared to typical daily scenario configuration solution. But it should be concerned that the optimal configuration while considering multi-swapping demand scenarios in our model is much more flexible because the extreme swapping demand like more concentrated in the temporal dimension and larger swapping demand in festival days is taken into account. The difference of configuration means that in order to meet the demand in extreme scenarios, more facilities should be equipped in BSS which results in there are a large number of batteries and chargers idled on other days like workdays. Therefore, how to use a good mechanism such as time of use price for swapping service fee to shape swapping demand more smooth to avoid these low-utilized facilities investment and improve BSS economic is an essential and meaningful problem needed to be investigated.

\subsection{Summary}

The results of case study prove the effectiveness of proposed model. According to the results of case study and impact analyses, some summaries and suggestions can be concluded as follows:

1) BSS has the potential to be a kind of demand response resources in order to absorb clean energy and shave charging power peak. BSS would be a participator in electricity market to provide many kind of services like G2V, V2G, and other kind of demand response services [28]. However, it needs more incentives for BSS to change the configuration decision and reschedule the charging arrangement, including the decline of battery's price, increasing the price difference between peak and valley price in grid power TOU price and increasing allowance for PV system to reduce price for purchasing PV energy.

2) The optimal operation strategy and configuration decision of BSS are both greatly influenced by the PV consumption bundling requirement. BSS needs

Table 7 The optimal configuration solutions under different scenarios

\begin{tabular}{lllll}
\hline Scenarios & Number of robots & Number of batteries & Number of chargers & $\begin{array}{c}\text { Profit/ } \\
\text { (yuan) }\end{array}$ \\
\hline Multi-swapping demand & 6 & 101 & 125 & $573,679.7$ \\
Single swapping demand & 3 & 51 & 72 & $1,511,402.5$ \\
\hline
\end{tabular}


to find an appropriate combination of PV capacity and PV consumption bundling requirement in contract with PV sellers to keep its profit at a satisfaction level.

3) The distribution characteristics of swapping demand have great influence on the equipment configuration planning for BSS. It is necessary to anticipate the fluctuation of BSS profit under multi-swapping demand scenarios at planning stage.

\section{Conclusions}

In this paper, we have proposed an optimization model of configuration and operation for BSS considering PV consumption bundling. There are several optimal solutions for components of BSS, including EV batteries, swapping robots and battery charging machines, and operation schedule suggestions can be derived. The scheme of proposed model is also a guidance to dig out demand response potential of BSS, in order to satisfy the expectation of multi-stakeholders in the market and is also a toolbox for BSS investor to configure facilities for future's operation with considering the uncertainties of PV generation and swapping demand. The case study results demonstrate that as the penetration of EVs increases, EV batteries are focused on as a kind of natural storages. It is reasonable and effective to excavate the potential of EV batteries to offer demand response by various technical means and incentive mechanism after satisfying swapping demand. What needs to be stressed is that the electricity price in the market and the SOCs of arriving EVs are also uncertain. Moreover, several types of EVs all need to be recharged at one EVs battery swapping station, one BSS should be able to provide different types of batteries [13]. The comprehensive planning model should be established considering different kinds of incentive mechanisms for BSS which may guide and change swapping demand in the market. It will be one of our future's work.

\section{Abbreviations}

BSS: Battery swapping station; EV: Electric vehicle

\section{Funding}

This work is supported by the National Natural Science Foundation of China (Grant No. 51207050).

\section{Authors' Contributions}

YC helped performing the case study and revised the manuscript. CZ contributed to the conception of this study and significantly to the modeling establishment process. Both authors read and approved the final manuscript.

\section{Authors' information}

Yu CHENG (1978-), female, Ph. D. degree. She is currently an Associate Professor with the School of Electrical and Electronic Engineering, North China Electric Power University. Her research interests include demand response, the theory and methods of electricity pricing, power system economy analysis.
Chengwei ZHANG (1992-), male, he is currently working toward the M.S. degree at the School of Electrical and Electronic Engineering, North China Electric Power University, Beijing, China. His research interests include demand response, electric vehicles.

\section{Competing interests}

The authors declare that they have no competing interests.

\section{Consent for publication}

Not applicable.

Ethics approval and consent to participate

Not applicable.

Received: 17 March 2017 Accepted: 6 June 2017

Published online: 19 July 2017

\section{References}

1. National Development and Reform Commission, National Energy Board, Ministry of industry and Information Technology, the Ministry of housing and urban construction ministry of housing (2015) Guidefor the development of electric vehicle charging infrastructure. Available via DIALOG http://www.sdpc.gov.cn/zcfb/zcfbtz/201511/t20151117_758762. html. Accessed 9 Oct 2015.

2. Yang, S. J., Yao, J. G., Kang, T., \& Zhu, X. Q. (2014). Dynamic operation model of the battery swapping station for EV (electric vehicle) in electricity market. Energy, 65, 544-549.

3. Gao, C. W., \& Wu, X. (2013). A survey on battery-swapping mode of electric vehicles. Power Syst Technol, 37(4), 891-898 (in Chinese).

4. Rao, R., Zhang, X. P., Xie, J., \& Ju, L. W. (2015). Optimizing electric vehicles users' charging behavior in battery swapping model. Applied Energy, 155, 547-559.

5. Xie, P. P., Li, Y. H., Zhu, L., Shi, D. Y., \& Duan, X. Z. (2016). Supplementary automatic generation control using controllable energy storage in electric vehicle battery swapping stations. IET Generation, Transmission \& Distribution, 10(4), 1107-1116.

6. Sun, L., Wang, X. L., Liu, W. J., Lin, Z. Z., Wen, F. S., Ang, S. P., et al. (2016) Optimisation model for power system restoration with support from electric vehicles employing battery swapping. IET Generation, Transmission \& Distribution, 10(3), 771-779.

7. Liu, N., Chen, Q. F., Lu, X. Y., Liu, J., \& Zhang, J. H. (2015). A charging strategy for PV-based battery switch stations considering service availability and selfconsumption of PV energy. IEEE Trans Industrial Electronics, 62(8), 4878-4889.

8. Sarker, M. R., Panzic, H., \& Oretga-Vazquez, M. A. (2015). Optimal operation and services scheduling for an electric vehicle battery swapping station. IEEE Trans Power Systems, 30(2), 901-910.

9. Miao, Y. Q., Jiang, Q. Y., \& Cao, Y. J. (2012). Operation strategy for battery swap station of electric vehicles based on microgrid. Autom Electr Power Syst, 36(15), 33-38 (in Chinese).

10. Tian, W. Q., \& He, J. X. (2012). Research on dispatching strategy for coordinated charging of electric vehicle battery swapping station. Power Syst Protect Control, 40(21), 114-119 (in Chinese).

11. Yang, S. J., Yao, J. G., Kang, T., \& Zhu, X. Q. (2014). Dynamic operation model of the battery swapping station for EV(electric vehicle) in electricity market. Energy, 65, 544-549.

12. Yang, Y. X., Hu, Z. C., \& Song, Y. H. (2012). Research on optimal operation of battery swapping and charging station for electric buses. Proc CSEE, 32(31), 35-42 (in Chinese).

13. Liu, N., Chen, Z., Liu, J., Tang, X., Xiao, X. N., \& Zhang, J. H. (2014). Multiobjective optimization for component capacity of the photovoltaic-based battery switch stations: Toswards benefits of economy and environment. Energy, 64, 779-792

14. Nian, L., Tang, X., Duan, S., \& Zhang, J. H. (2013). Capacity Optimization method for PV-based battery swapping stations considering second-use of electric vehicle batteries. Proc CSEE, 33(4), 34-44 (in Chinese).

15. Gao, C. W., Wu, X., Xue, F., \& Liu, H. C. (2013). Demand Planning of Electric Vehicle Battery Pack Under Battery Swapping Mode. Power Syst Technol, 37(7), 1783-1791 (in Chinese).

16. Jing Z, Fang L, Lin S, Shao W. (2014). Modeling for Electric Taxi Load and Optimization Model for Charging/Swapping Facilities of Electric Taxi. Transportation Electrification Asia-Pacific IEEE, 1-5 
17. Wang L, Wang X, Sun Q, Lai L. (2015). The Service Modeling of EV Charging/ swapping Station and its Cost Benefit Analysis. 10th International Conference on Advances in Power System Control, Operation \& Management (APSCOM), 31-37

18. Zheng, Y., Dong, Z. Y., Xu, Y., Meng, K., Zhao, J. H., \& Qiu, J. (2013). Electric Vehicle Battery Charging/Swap Stations in Distribution Systems: Comparison Study and Optimal Planning. IEEE Trans Power Systems., 29(1), 221-229.

19. Zhang, H., Hu, Z., Xu, Z., \& Song, Y. (2016). Optimal Planning of PEV Charging Station With Single Output Multiple Cables Charging Spots. IEEE Trans Smart Grid., 99, 1-10.

20. Gharbaoui M, Martini B, Bruno R. (2013). for efficient usage of an EV charging infrastructure deployed in city parking facilities. International Conference on ITS Telecommunications, 384-389

21. Lu X, Liu N, Huang Y, Zhang J, Zhou N. (2014). Optimal Configuration of EV Battery Swapping Station Considering Service Availability. International Conference on Intelligent Green Building and Smart Grid IEEE, 1-5

22. Sun B, Tan X, Tsang D. Optimal Charging Operation of Battery Swapping and Charging Stations with QoS Guarantee. IEEE Trans Smart Grid, 99:1-13

23. Zhang L, Lou S, Wu Y, Lin Y, Bin H. (2014). Optimal Scheduling of Electric Vehicle Battery Swap Station Based on Time-of-Sse Pricing. Power and Energy Engineering Conference IEEE, 1-6

24. Zhang CH., Meng JS, Cao YX, Cao X, Huang Q, Zhong, QC. (2012). The Adequacy Model and Analysis of Swapping Battery Requirement for Electric Vehicles. IEEE Power and Energy Society General Meeting, 1-5

25. Dai, Q., Cai, T., Duan, S., \& Zhao, F. (2014). Stochastic Modeling and Forecasting of Load Demand for Electric Bus Battery-Swap Station. IEEE Trans Power Delivery, 29(4), 1909-1917.

26. Zhang, Q. D., Huang, X. L., Chen, Z., Chen, L. X., \& Xu, Y. P. (2015). Research on control strategy for the uniform charging of electric vehicle battery swapping station. Transactions of China Electrotechnical Society, 30(12), 447453 (in Chinese).

27. Chen, Y. Z., Zhang, B. H., Wang, J. H., Mao, B., Fang, R. C., Mao, C. X., et al. (2011). Active control strategy for microgrid energy storage system based on short-term load forecasting. Power Syst Technol, 35(8), 35-40 (in Chinese).

28. Yao, W. F., Zhao, J. H., Wen, F. S., Xue, Y. S., \& Xin, J. B. (2012). A charging and discharging dispatching strategy for electric vehicles based on bi-level optimization. Autom Electr Power Syst, 36(11), 30-37 (in Chinese).

\section{Submit your manuscript to a SpringerOpen ${ }^{\circ}$ journal and benefit from:}

- Convenient online submission

- Rigorous peer review

- Open access: articles freely available online

- High visibility within the field

- Retaining the copyright to your article

Submit your next manuscript at $\boldsymbol{s p r i n g e r o p e n . c o m ~}$ 